\title{
Knowledge, practice, and barriers toward cervical cancer screening in Elmina, Southern Ghana
}

This article was published in the following Dove Press journal:

International Journal of Women's Health

24 December 2014

Number of times this article has been viewed

\section{Nancy Innocentia Ebu' \\ Sylvia C Mupepi ${ }^{2}$ \\ Mate Peter Siakwa' \\ Carolyn M Sampselle ${ }^{3}$}

'University of Cape Coast, School of Nursing, Cape Coast, Ghana; ${ }^{2}$ Kirkhof College of Nursing, Grand Valley State University, Grand Rapids, MI, USA;

${ }^{3}$ School of Nursing, University of

Michigan, Ann Arbor, MI, USA
Correspondence: Nancy Innocentia Ebu University of Cape Coast, School of Nursing, Cape Coast, Ghana

Tel +23354 II4 5193

Email nancysrn@rocketmail.com
Aims: The aims of this study were: 1) to assess the level of knowledge of women about Pap smear tests, 2) to determine the practices of women regarding Pap smear tests, and 3) to determine the barriers to Pap smear tests in Elmina, Ghana.

Methods: A cross-sectional study was conducted with 392 randomly selected sexually active females aged 10-74 years using structured interview questions. The Institutional Review Board of the University of Cape Coast gave ethical approval for the study and informed consent was obtained from participants. Data were analyzed with SPSS software (v19.0) using frequencies, chi-square test, and exploratory factor analysis.

Results: The results revealed that $68.4 \%$ had never heard about cervical cancer, $93.6 \%$ had no knowledge on the risk factors, nine (2.3\%) reported multiple sexual partners and being sexually active as risk factors, and $92 \%$ did not know about the prevention and treatment of cervical cancer. The majority (97.7\%) had never heard of the Pap smear test. Only three $(0.8 \%)$ women out of 392 had had a Pap smear test. Reasons for seeking a Pap smear test included referral, fear of cervical cancer, and radio campaigns. A significant association was found between institutional and personal barriers and having a Pap smear test.

Conclusion: Comprehensive education on cervical cancer screening and removal of access barriers are critical in reducing risk associated with the disease and promoting women's health.

Keywords: women, cervical screening, awareness, factors, community, developing countries

\section{Introduction}

Cancer is a major cause of death worldwide. In 2008, 12.7 million cases of the disease were diagnosed globally and 7.6 million individuals lost their lives as a result of the condition. ${ }^{1}$ Cervical cancer is a leading public health concern globally. Although a decline has been observed in cervical cancer incidence and deaths in the developed world over the past 20 years, there has not been a significant change in the same key indicators in poor resource settings. In Ghana, cervical cancer is the most common cancer affecting women, with $50.5 \%$ attributed to human papillomavirus (HPV) types 16 and 18 , and is the cause of $16 \%$ of mortality due to cancer. ${ }^{2}$

The World Health Organization (WHO) has estimated additional cases of cervical cancer to be over 5,000 in Ghana with at least 3,300 deaths every year by $2025 .{ }^{3}$ It is difficult to ignore the problem of cervical cancer in Ghana. Greater proportions of women of reproductive age are at high risk of developing cervical cancer as there is no systematic national screening or treatment available. ${ }^{2-4}$ Cervical cancer screening services in Ghana are not common and are restricted as the test is done in few public health facilities in the country and is patronized by referrals and a few who know 
about Pap smears. Adanu ${ }^{4}$ and Gaffikin et $\mathrm{al}^{5}$ reported that the cervical cancer screening situation in Ghana was not helped by the lack of a comprehensive national screening program, thus limiting the number of women who receive screening. Adanu ${ }^{4}$ and Duda et $\mathrm{al}^{6}$ reported low rates of patronage of cervical cancer screening services among a cross-section of women in Accra, Ghana.

Nonetheless, routine tests with Pap smears can greatly minimize the risks of dying from cervical cancer. Pap smear tests have decreased annual worldwide mortality rates associated with cervical cancer by approximately $2 \%$ each year since its introduction in $1941 .^{7}$ It is known to have reduced the overall mortality rate by $74 \%$. The test is considered the most effective cancer-screening technique ever discovered. ${ }^{7}$ Asides the Pap smear, alternative screening approaches that have been explored for the prevention of cervical cancer in low-middle income countries include visual inspection with acetic acid (VIA), visual inspection with Lugol's iodine (VILI), cervicography, and speculoscopy. These approaches are simple, yet cost-effective, and could promote a "screen and treat" mechanism that entails diagnosis and treatment at a single visit. ${ }^{8,9}$

Utilization of the Pap smear test for cervical cancer prevention and control would contribute to the attainment of the Millennium Development Goals through universal access to sexual and reproductive health services to improve women's health. ${ }^{2}$ For instance, in Mozambique it is part of the national family planning program. In Cote d'lvoire, Zambia, and Botswana, cervical cancer screening services are incorporated into HIV programs. These integrations have resulted in high rates of screening uptake. ${ }^{10}$

Although cervical cancer is preventable, and knowledge of the condition and early screening might decrease the mortality associated with it, most women report to the hospital with an advanced form of the disease due to lack of awareness and community level interventions to encourage screening. Some empirical studies in cervical cancer screening in Ghana have been carried out in urban and university settings and among women who attended hospitals. For instance, some studies examined the knowledge and attitudes of college students regarding cervical cancer screening. ${ }^{4-11}$ Studies conducted by Abotchie and Shokar ${ }^{11}$ and Adanu et al $^{12}$ have suggested that women did not have adequate information on what cervical cancer screening was about as well as local screening initiatives. As a result, only half of the study samples perceived themselves to be at risk. In addition, Quentin et al $^{13}$ argued that the high cost of screening and treatments were important barriers toward seeking cervical cancer screening tests in Kumasi, Ghana. To date, no study has exclusively studied the knowledge, practice, and barriers regarding cervical cancer screening among women in Ghana. This study is the first to document such important information that might be crucial in facilitating planning community level interventions necessary to reduce morbidity and mortality from the disease.

\section{Methods}

Elmina is situated in the Central Region of Ghana, which is second to the Upper West in the proportion of females who engage in sexual activity before 15 years of age. ${ }^{14}$ Most of these activities are high-risk behaviors. ${ }^{15}$ The Ghana Demographic and Health Survey 2008 reported that only $28.6 \%$ of women in the Central Region of Ghana who had higher risk sexual intercourse did so using a condom. ${ }^{16}$ This might predispose young girls to HPV. Additionally, Ghana has an estimated HIV prevalence of $1.4 \%$. The Central Region of Ghana recorded an HIV prevalence of $4.7 \%$ in the HIV Sentinel Survey. ${ }^{17}$ It is already known that HIV and HPV act in synergy to cause cervical neoplasia. ${ }^{18-21}$

\section{Population}

According to the 2010 Population and Housing census statistics, Elmina has a total female population of 20,305. ${ }^{15}$ The target population for this study included women who are 10-74 years and are sexually active. Although screening is not recommended for 10-year-olds, they were included in the study as we were testing their knowledge of risk factors for cervical cancer; if they were knowledgeable on the subject, the likelihood of them seeking cervical screening at the appropriate time might be greater. The sample included pregnant women as well as the elderly. The women were residents of Elmina who were available at the time of data collection. The sample excluded women who normally do not reside in Elmina and those who were mentally challenged. The criteria for determining the sample size for this study was based on the purpose of the study, size of the population, level of precision, the level of confidence or risk, and the degree of variability in the attributes being measured. ${ }^{19}$

\section{Sampling}

Cluster or multistage sampling design was used in this study. First, random sampling was used to select the study communities. Random sampling is a form of probability sampling technique where each unit of the population has an equal chance of inclusion in the sample. ${ }^{20}$ Based on the 2010 census data, Elmina has a total of 15 communities. 
Using the ballot approach, five communities (Bronyibima, Bantoma, Elmina traditional, Pershie, and Tetterkessimu) were randomly chosen out of the 15 .

Second, the probability proportionate to size approach was employed in selecting the households within each community. In order to select the study participants within the households in each community, a coin was tossed and the direction where the head pointed was used to select the first household. The systematic sampling method was used by including every fourth household in the study. It was expected that at least two-thirds of those households would have women that met the inclusion criteria. Maps were available delineating the geographical area for the study and indicating major roads as well as individual households.

Recruitment of subjects was conducted at churches, community centers, health centers, and schools by word of mouth and on the local radio. In order to get women who fell within the inclusion criteria to participate in the study at the household level, interviewers inquired from heads of households if they had such women in their households. Data were collected from women who were available at the time of data collection. For those who had either gone to work or were not available, effort was made to obtain data from them at a later date (early in the morning or in the evening when they were at home).

\section{Data collection}

A structured interview schedule was used to collect relevant data for the study and was adopted from that used by Mupepi et al. ${ }^{21}$ The structured interview schedule offered a closed set of responses from which the respondents could choose. The structured interview schedule identified the sociodemographic characteristics of respondents, their knowledge and practice of cervical cancer screening, and the barriers toward cervical cancer screening. The instrument was pre-tested among 20 women in a nearby community in order to check adequacy of the questions in terms of wording, clarity, and ambiguity. ${ }^{20}$ To ensure face validity and content validity, the questions were constructed congruently with the specific research questions and the literature review. The instrument was given to two independent researchers to confirm its validity. Cronbach's coefficient alphas for the various scales were: knowledge scale: 0.918 , practice scale: 0.833 , and the barriers scale: 0.795 . Cronbach's coefficient alpha measures internal consistency of a scale. ${ }^{20}$

The instrument was administered to women that met the inclusion criteria. The interviewers were professional female nurses who could speak the Fante language who were trained to assist with the household data collection. The instrument had predetermined answers or options for respondents to choose from, and few respondents chose "other". This was necessary as the study was conducted in a predominately Fante urban community. The instrument was administered in the local language to the study participants in their homes. The participants were divided into two groups based on whether they had knowledge or lacked knowledge of cervical cancer. Those who lacked knowledge were taught onsite, to enable them to continue participating in the study. An educational pamphlet developed by the Ministry of Health was used to educate those who lacked understanding about the disease and screening facilities available. Group 1 included 98\% (384) of the women who did not have correct understanding of cervical cancer screening and lacked knowledge, and group 2 included 2\% (eight) women who had correct understanding of this topic. Ethically, group 1 participants benefitted from the study through the knowledge gained after they were taught about the disease. It is important to mention that the responses provided by group 1 participants were hypothetical as opposed to real life experiences.

Data were collected from mid-November to midDecember, 2013. Data were analyzed with SPSS software (v19.0; IBM Corporation, Armonk, NY, USA). Descriptive and inferential statistics such as percentages, Chi-square test, and factor analysis were used to determine the nature of the problem.

\section{Ethical consideration}

Ethical approval for the study was obtained from the Institutional Review Board of the University of Cape Coast. Permission was sought from community leaders and informed consent obtained from the study participant before embarking on data collection. Participants aged 17 years and below were asked to sign the assent form (this is a form signed by all children 17 years and below participating in research and is sought in addition to parental consent). The data collectors also signed a confidentiality statement. This was to protect the rights of the subjects involved in the study and ensured a high level of integrity in the research process.

\section{Results}

Table 1 illustrates the background characteristics of the respondents. Females aged 10-74 years participated in the study. Thirty-two point seven percent of the women were aged 20-29 years and 107 (27.3\%) were aged 30-39 years. Twenty-nine percent of the respondents were aged 40 years and above. This means that the majority of the 
Table I Sociodemographic data of respondents $(n=392)$

\begin{tabular}{|c|c|c|}
\hline Variables & Frequency & Percentage \\
\hline \multicolumn{3}{|l|}{ Age group (years) } \\
\hline $10-19$ & 45 & 11.5 \\
\hline $20-29$ & 128 & 32.7 \\
\hline $30-39$ & 107 & 27.3 \\
\hline $40-49$ & 58 & 14.8 \\
\hline $50-59$ & 39 & 9.9 \\
\hline$\geq 60$ & 15 & 3.8 \\
\hline \multicolumn{3}{|l|}{ Marital status } \\
\hline Married & 162 & 41.3 \\
\hline Single & 95 & 24.2 \\
\hline Cohabiting & 84 & 21.4 \\
\hline Widowed & 27 & 6.9 \\
\hline Divorced & 24 & 6.1 \\
\hline \multicolumn{3}{|l|}{ Polygamous marriage } \\
\hline Yes & 51 & 13.0 \\
\hline No & 341 & 87.0 \\
\hline \multicolumn{3}{|l|}{ Place of residence } \\
\hline Elmina traditional & $|5|$ & 38.5 \\
\hline Bronyibima & 87 & 22.2 \\
\hline Pershie & 64 & 16.3 \\
\hline Teterkessimu & 59 & 15.1 \\
\hline Bantoma & 31 & 7.9 \\
\hline \multicolumn{3}{|l|}{ Ethnicity } \\
\hline Fante & 341 & 87.0 \\
\hline $\mathrm{Ga}$ & 10 & 2.6 \\
\hline Ewe & 8 & 2.0 \\
\hline Gawu & 8 & 2.0 \\
\hline Asante & 7 & 1.8 \\
\hline Others & 18 & 4.6 \\
\hline \multicolumn{3}{|l|}{ Religion } \\
\hline Christianity & 342 & 87.1 \\
\hline Islam & 47 & 12.0 \\
\hline Hindu & I & 0.3 \\
\hline Atheist & I & 0.3 \\
\hline Others & I & 0.3 \\
\hline \multicolumn{3}{|l|}{ Educational level } \\
\hline No formal education & 70 & 17.9 \\
\hline Primary & 88 & 22.4 \\
\hline Junior high school/middle school & 170 & 43.4 \\
\hline Senior high school & 40 & 10.2 \\
\hline College diploma & 13 & 3.3 \\
\hline University degree & 11 & 2.8 \\
\hline \multicolumn{3}{|l|}{ Occupation } \\
\hline Petty trading & 158 & 40.3 \\
\hline Fishmonger & 48 & 12.3 \\
\hline Dressmaking & 37 & 9.4 \\
\hline Hairdressing & 25 & 6.4 \\
\hline Others & 124 & 31.6 \\
\hline \multicolumn{3}{|l|}{ Employment status } \\
\hline Self-employed & 278 & 70.9 \\
\hline Unemployed & 47 & 12.0 \\
\hline Government employee & 27 & 6.9 \\
\hline Student & 17 & 4.3 \\
\hline Housewife & 9 & 2.3 \\
\hline Retired & 7 & 1.8 \\
\hline Private sector & 7 & 1.8 \\
\hline
\end{tabular}

Table I (Continued)

\begin{tabular}{|c|c|c|}
\hline Variables & Frequency & Percentage \\
\hline \multicolumn{3}{|c|}{ Monthly household income } \\
\hline$<\mathrm{GH} \not 157$ & 225 & 57.4 \\
\hline $\mathrm{GH} \not \subset \mid 57-200$ & 108 & 27.6 \\
\hline $\mathrm{GH} \not 20 \mathrm{I}-500$ & 42 & 10.7 \\
\hline $\mathrm{GH} \phi 50 \mathrm{I}-900$ & 13 & 3.3 \\
\hline$>\mathrm{GH} \phi 900$ & 4 & 1.0 \\
\hline \multicolumn{3}{|l|}{ Social class/status } \\
\hline Upper middle class & 4 & 1.0 \\
\hline Middle class & 12 & 3.1 \\
\hline Lower middle class & 19 & 4.8 \\
\hline Skilled working class & 63 & 16.1 \\
\hline Working class & 211 & 53.8 \\
\hline Nonworking class & 83 & 21.2 \\
\hline
\end{tabular}

respondents were still within the reproductive age group. In terms of their marital status, $41 \%$ of the respondents were married, $22 \%$ cohabited, $7 \%$ widowed, and $6 \%$ divorced. The data also revealed that $13.0 \%$ of the women were in polygamous marriages. Most of the respondents resided at Elmina Traditional and Bronyibima, with the most dominant tribe among them being Fante $(87.0 \%)$. There were also other ethnic groups, including Ga, Ewe, Gawu, and Igbo. This shows that the respondents were from different ethnic backgrounds, including Nigerians. Christians and Muslims constituted the majority of the women with $87 \%$ and $12 \%$, respectively. Although 70 (17.9\%) of the respondents were formally uneducated, 170 (43.4\%) and eleven (2.8\%) had acquired junior high school or middle school education and university degrees, respectively. A significant number of them had also obtained primary, senior high school, and college education. The respondents were mainly petty traders and fishmongers. About $80 \%$ of them reported that they were self-employed, while the others were either unemployed or worked in the public sector. Table 1 shows that 225 (57.4\%) of the respondents earned below the current national monthly income of GH $\phi 157.00$ (US\$50) as their total household income, while 108 (27.6\%) earned GH $₫ 157-200$ (US\$50-64). The results further showed that only $1 \%$ earned at least GH $\notin 901$ per month for the family (US\$290). Similarly, more than half of the respondents were in the working class. The demographic and socioeconomic characteristics of the respondents portray the peri-urban nature of the community.

More than half (68.4\%) of the women had never heard about cervical cancer. The majority (93.6\%) of the respondents had no knowledge of cervical cancer risk factors. Nine (2.3\%) indicated that being sexually active could cause this type of cancer. In addition, nine (2.3\%) of the respondents 
reported that having multiple sexual partners could result in cervical cancer, while five $(1.3 \%)$ identified that having a sex partner who had other partners might be responsible for cervical cancer. However, none of the respondents identified cigarette smoking and tobacco chewing as possible risk factors in cervical cancer infection. Out of the 392 respondents, only $23(5.9 \%)$ knew that cancer of the cervix could be transmitted through sex, while six (1.5\%) disagreed. About $93 \%$ of the respondents had no knowledge of the mode of transmission of this disease. With regard to whether cervical cancer could be treated and prevented, $92 \%$ of the respondents lacked knowledge.

The overwhelming majority $(384 ; 97.7 \%)$ of the respondents had never heard about the Pap smear test. However, eight $(2 \%)$ of the respondents had a correct understanding of Pap smears. Of the respondents who had undergone the Pap smear test in the study, only three $(0.8 \%)$ had been screened. The three respondents who had had a Pap smear test reported that they were referred by their health care providers. Other reasons that emerged for seeking a Pap smear test included fear of cervical cancer and messages from radio campaigns. The results suggest that none of the respondents had voluntarily availed themselves for this test.

The main barriers identified by respondents for not seeking Pap smear tests were institutional and personal, as shown in Table 2. These were lack of screening sites, screening sites being too far away, limited information on cervical cancer, and absence of health education programs. The personal factors were lack of knowledge about the Pap smear test and the facilities where it can be carried out. This is because these two barriers had eigenvalues greater than 2 and had accounted for $16.25 \%$ and $12.73 \%$ of the total variation in the data, respectively. This means that these are the most devastating barriers. Specifically, items such as "the screening sites are too far from where I live" and "there is limited information on cervical cancer in the community" were dominant in the institutional barriers to the Pap smear test among the respondents. With regard to the personal barriers, the respondents lacked adequate knowledge about the test and where it could be done. Similarly, negative beliefs, social, and negative misconception barriers collectively explained about $47 \%$ of the total variation.

The negative beliefs identified by the majority of the respondents were that the Pap smear test was embarrassing and painful. The social barrier identified was that religion and cultural values deterred women from seeking the Pap smear test. In addition, women's partners not allowing their spouse to seek the Pap smear was identified as a social barrier. The
Table 2 Barriers hindering cervical cancer screening among respondents

\begin{tabular}{|c|c|c|}
\hline Scale items & Loadings & Barrier factors \\
\hline $\begin{array}{l}\text { There are no screening sites in the } \\
\text { community }\end{array}$ & 0.849 & Institutional barriers \\
\hline $\begin{array}{l}\text { There is limited information on } \\
\text { cervical cancer in the community }\end{array}$ & 0.873 & Institutional barriers \\
\hline $\begin{array}{l}\text { The screening sites are too far } \\
\text { from where I live }\end{array}$ & 0.939 & Institutional barriers \\
\hline $\begin{array}{l}\text { There are no health education } \\
\text { programs to promote screening }\end{array}$ & 0.376 & Institutional barriers \\
\hline $\begin{array}{l}\text { I do not know what the test is all } \\
\text { about }\end{array}$ & 0.944 & Personal barriers \\
\hline $\begin{array}{l}\text { I do not know of any screening } \\
\text { sites }\end{array}$ & 0.948 & Personal barriers \\
\hline Pap smear test is embarrassing & 0.896 & $\begin{array}{l}\text { Negative belief } \\
\text { barriers }\end{array}$ \\
\hline Pap smear test is painful & 0.885 & $\begin{array}{l}\text { Negative belief } \\
\text { barriers }\end{array}$ \\
\hline $\begin{array}{l}\text { I have not engaged in risky sexual } \\
\text { behaviors in the past }\end{array}$ & 0.673 & Social barriers \\
\hline $\begin{array}{l}\text { It is against my religious beliefs and } \\
\text { cultural values to go for screening }\end{array}$ & 0.782 & Social barriers \\
\hline $\begin{array}{l}\text { My partner would not allow me to } \\
\text { go for screening }\end{array}$ & 0.715 & Social barriers \\
\hline $\begin{array}{l}\text { I do not feel at risk of getting } \\
\text { cervical cancer }\end{array}$ & 0.775 & $\begin{array}{l}\text { Negative } \\
\text { misconception barriers }\end{array}$ \\
\hline $\begin{array}{l}\text { I am not sexually active so do not } \\
\text { need to go for a Pap smear }\end{array}$ & 0.864 & $\begin{array}{l}\text { Negative } \\
\text { misconception barriers }\end{array}$ \\
\hline $\begin{array}{l}\text { I am scared of a cancer diagnosis } \\
\text { and treatment }\end{array}$ & 0.759 & $\begin{array}{l}\text { Fatalistic } \\
\text { misconception barriers }\end{array}$ \\
\hline $\begin{array}{l}\text { Past vaginal examination tests have } \\
\text { been uncomfortable }\end{array}$ & 0.739 & $\begin{array}{l}\text { Fatalistic } \\
\text { misconception barriers }\end{array}$ \\
\hline $\begin{array}{l}\text { It is difficult to schedule a test } \\
\text { appointment }\end{array}$ & 0.580 & $\begin{array}{l}\text { Fatalistic } \\
\text { misconception barriers }\end{array}$ \\
\hline $\begin{array}{l}\text { I cannot afford the cost of } \\
\text { screening }\end{array}$ & 0.934 & Financial barriers \\
\hline $\begin{array}{l}\text { Pap smear is not covered by health } \\
\text { insurance }\end{array}$ & 0.188 & Financial barriers \\
\hline
\end{tabular}

negative misconceptions identified were that women did not feel at risk and therefore felt no need for Pap screening and also those that reported not being sexually active felt no need for the Pap test.

Further barriers revealed by the factor analysis were fatalistic misconception and financial barriers. The fatalistic misconception barriers comprised of items like "I am scared of a cancer diagnosis and treatment", and "past vaginal examination tests have been uncomfortable". The financial barriers identified included the inability to afford the cost of the test since it is not covered by the National Health Insurance Scheme.

The study revealed that not having Pap smear tests had significant associations with all seven barriers at the 5\% significance level as shown in Table 3. This confirmed the 
negative implications of these barriers on respondents' decision not to undergo a Pap smear test for cervical cancer. Confirming the results from the factor analysis, the Chi-square test also revealed that institutional barriers were the main barriers to seeking a Pap smear test, followed by personal barriers, since they had the highest Chi-square values of $28.965(d f=4$; $P=0.000)$ and $26.055(d f=5 ; P=0.000)$, respectively.

\section{Discussion}

The background characteristics of the respondents are necessary in contextualizing the study. The study was conducted in a predominantly Fante population. The Fantes belong to a major ethnic group: the Akan in Ghana. A significant proportion $(341 ; 87.1 \%)$ were Christians, followed by 47 (12\%) Muslims. This supports the claim that $71.2 \%$ of Ghanaians are Christians, with $17.6 \%$ being Muslims. ${ }^{22} \mathrm{~A}$ greater proportion $(128 ; 32.7 \%)$ of the participants fell within the $20-29$ years age group. This is consistent with the findings of the Ghana Demographic and Health Survey 2008, which suggested that more than half of Ghanaian women are under the age of 30 years. ${ }^{16}$ This age structure shows that the sample consisted of a young population, which could have high fertility. This calls for the provision of reproductive health services to meet their sexual and reproductive health needs.

Knowledge of women on cervical cancer and the Pap smear test are critical in cervical cancer prevention strategies. The results of this study shows that a great proportion (68.4\%) of the sampled population had never heard of cervical cancer. This finding is consistent with other research, which reported a lack of knowledge about cervical cancer among women. ${ }^{21,27,28}$

Education on cervical screening through the mass media and health talks in delivering health care are imperative to informing women about cervical cancer and the facilities available for them. Opportunistic screening in health facilities could be encouraged to improve screening uptake, especially in women within the lower socioeconomic groups. ${ }^{13-30}$

Table 3 Association between Pap smear test and the barriers to Pap test

\begin{tabular}{llll}
\hline Barriers & $\begin{array}{l}\text { Chi-square } \\
\text { values }\end{array}$ & df & P-value \\
\hline Personal barriers & 26.055 & 5 & 0.000 \\
Negative belief barriers & 21.915 & 4 & 0.000 \\
Fatalistic misconception barriers & 20.005 & 6 & 0.000 \\
Negative misconception barriers & 20.965 & 4 & 0.000 \\
Financial barriers & 27.533 & 5 & 0.000 \\
Social barriers & 19.519 & 4 & 0.001 \\
Institutional barriers & 28.965 & 4 & 0.000 \\
\hline
\end{tabular}

In this study, the majority of the respondents (93.6\%) lacked knowledge of risk factors for cervical cancer. Previous studies have cited lack of knowledge and awareness about the risk factors of cervical cancer as important factors impacting screening uptake. ${ }^{31-33,45}$ Were et $\mathrm{al}^{33}$ reported a significant association between perceived risk of cervical cancer and having the intent for cervical screening. A possible explanation for this result might be the low public awareness of cervical cancer in Ghana. ${ }^{4}$ In addition, the status of women in the Ghanaian society could affect their pattern of seeking preventive health services. In most households, women are not actively involved in decision making and they might not be in a position to have sufficient financial resources to engage in appropriate health promotion interventions such as cervical screening; this generally deprives Ghanaian woman of equity, dignity, and equality. ${ }^{34}$ It is evident that information about cervical cancer needs to be made available to women through mass campaigns about the disease, especially specific preventive measures and the screening facilities available. ${ }^{24-36}$

Nine $(2.3 \%)$ participants indicated that being sexually active and having multiple sexual partners could predispose an individual to cervical cancer. This finding is consistent with several previous studies ${ }^{25-35}$ that reported association of HPV and cervical cancer to sexual activity. ${ }^{21-37}$ A significant association has been found between having multiple sex partners and perceived risk of cervical cancer. ${ }^{26-33}$ According to the WHO, cervical cancer is caused by HPV, which is a sexually transmitted infection and mostly affects sexually active men and women. ${ }^{3}$ However, in the current study, only $23(5.9 \%)$ knew that cancer of the cervix could be transmitted sexually. This implies that a greater proportion of sexually active women might acquire HPV through sex without them knowing the source of the infection.

Awareness of the Pap smear test was low $-97.7 \%$ of the respondents had never heard about the Pap smear test. This is consistent with the findings of previous studies, ${ }^{4-29}$ which reported awareness about the Pap smear to be low among samples of Nigerian, Zimbabwean, and Ghanaian women. In the present study, only $2 \%$ had correct understanding of Pap smears, ie, they could describe the test and identify facilities where one can obtain such services. This affirmed the findings of Paolino and Arrossi, ${ }^{38}$ in which a significant proportion $(49 \%)$ of those who had been screened had inadequate knowledge about Pap smears. In Ghana and other developing countries, there is poor institutional framework to promote screening. ${ }^{13}$ This is different from industrialized nations, which have largely succeeded in implementing successful 
programs..$^{5}$ In this study, $92 \%$ of the respondents indicated that cervical cancer cannot be treated and prevented. This is consistent with the findings of Eze et al, ${ }^{25}$ who reported that few women had knowledge on the prevention of cervical cancer. Meanwhile, in high income countries, availability of information on preventive strategies and treatment modalities has decreased the mortality of cancer of the cervix. ${ }^{39-40}$

Despite strong evidence that the Pap smear test is an appropriate method for increasing early intervention opportunities and decreasing the incidence and mortality associated with cervical cancer, ${ }^{3}$ many women in low-middle income countries have not availed themselves for screening. In this study, out of the 392 respondents, only three $(0.8 \%)$ had had the Pap smear test. Studies conducted earlier have reported low rates of Pap smear screening among women. ${ }^{21-41}$ A possible explanation is that women will engage in cervical screening if they are well-informed about it and the enabling factors are present to facilitate effective screening uptake. Chirenje et $\mathrm{al}^{42}$ indicated that in Zimbabwe, more than $95 \%$ of health care institutions had basic infrastructure to conduct cervical screening, but absence of clear policy, procedures, and competent cytotechnicians had affected utilization of cervical screening facilities. In Ghana, a lack of policy on mass screening could be contributing to low screening rates. Of those who had been screened, all three stated that they were referred. This suggests that respondents did not voluntarily avail themselves for the test. Earlier works have reported that referral and recommendations by a doctor are strong motivators for participating in cervical cancer screening programs..$^{23,43,44}$ While these are important factors, fear of knowing one had cervical cancer, being offering a Pap smear, and then obtaining an abnormal test result discouraged women from utilizing screening tests in Kenya, Estonia, and Qatar. ${ }^{33-46}$

The current study was unable to identify the fact that women participated in cervical screening as part of routine visits to health facilities and that their husbands might encourage them as has been reported in previous studies. ${ }^{35-47}$ Interesting findings in a study conducted among men in an urban area in Ghana revealed that most men expressed their willingness to provide spousal support for cervical screening if they had more information about the disease and the screening methods. ${ }^{48}$

Several factors could deter women from adopting appropriate health-seeking behaviors. The majority 348 (89.4\%) of the respondents indicated that their past vaginal examinations had been uncomfortable. Painful screening experiences and embarrassment with genital examination have been cited as factors that inhibit participation. ${ }^{33-44}$ In an earlier study, Waller et a ${ }^{49}$ identified fear of pain, feelings of embarrassment, unknown outcome of screening, difficulty scheduling an appointment, not being sexually active, and not trusting the test as barriers to cervical screening. Three hundred and eighty-seven $(99.4 \%)$ of the respondents in this study were of the view that screening facilities were not available in the community. The lack of access to health care, for instance, unavailability of screening sites and long distance to facilities influenced Pap smear screening behavior among women. ${ }^{25,35,50}$ Ezem $^{41}$ and Mutyaba et al ${ }^{51}$ pointed out that lack of awareness was a key factor preventing women from participating in cervical cancer screening, and in the present study, 329 (84.5\%) lacked knowledge about the Pap smear test. Previous studies have reported similar findings. ${ }^{29,30,52}$ This study further revealed that $97 \%$ of the respondents could not afford the cost of Pap smears as it is not covered by the National Health Insurance Scheme.

In the present study, institutional and personal factors were the main barriers regarding seeking Pap smear tests in Elmina. These barriers could impact the health-seeking behaviors of women at the community level. Evidence suggests that inadequate information on cervical cancer screening at the community level could be an important barrier in low-middle income countries in sub-Saharan Africa. ${ }^{1}$ Women could lack knowledge about where to access screening services. ${ }^{28}$ The personal barriers identified were that respondents lacked knowledge of screening sites and what the Pap test was about. Several studies have documented a low level of awareness of cervical cancer screening in developing



\section{Conclusion}

Cervical cancer is a problem of global health concern. Cervical cancer screening services such as the Pap smear test might be effective in detecting early precancerous lesions. However, many women in low-middle income countries may not be in a good position to access these services due to various forms of inequalities. This research has raised numerous practical and policy concerns. The majority of the women lacked knowledge about cervical cancer and the Pap smear test. The respondents lacked knowledge about cervical cancer risk factors, treatment, and prevention strategies. Personal and institutional barriers hindering the use of Pap smear services in Elmina were lack of awareness about the Pap smear test, the high cost of Pap smear screening, past vaginal examination being uncomfortable, and unavailability of screening facilities. Political commitment is needed to initiate 
culturally accepted cervical cancer screening programs and to address the numerous access barriers women encounter in order to promote their health. Community leaders, women, and politicians need to agree on a policy that will facilitate cervical screening; Pap smears should be accorded priority like other Maternal and Child Health Programs.

\section{Limitations of the study}

Some of the responses are based on hypothetical experiences as opposed to real life experiences.

\section{Acknowledgments}

The authors would like to acknowledge the contributions made by Professor Janet Gross and Mr Kingsley Asare Pereko of the University of Cape Coast.

\section{Author contributions}

NIE conceptualized, conducted the whole study, and entered and cleaned the data. NIE, SCM, MPS, and CMS critically reviewed the entire study and made useful contributions in the analysis and interpretation of data. SCM supervised all aspects of the research process. NIE drafted the manuscript, which was revised by SCM, MPS and CMS. The final manuscript was reviewed by all authors for important intellectual content.

\section{Disclosure}

The authors report no conflicts of interest in this work.

\section{References}

1. World Health Organization. WHO Country Cooperation Strategy 2008-2011: Ghana. Brazzaville, Republic of Congo: WHO Regional Office for Africa; 2012. Available from: http://www.who.int/countryfocus/ cooperation_strategy/ccs_gha_en.pdf. Accessed October 21, 2014.

2. Ghana Health Service. Non-communicable Disease Control Programme: Strategies for Cervical Cancer Prevention in Ghana: Planning Meeting and Training of Health Staff for HPV Demo Vaccination in Ghana. Cape Coast, Ghana: Ghana Health Service; 2013.

3. World Health Organization. WHO Guidance Note: Comprehensive Cervical Cancer Prevention and Control. A Healthier Future for Girls and Women. Geneva, Switzerland: World Health Organization; 2013. Available from: http://apps.who.int/iris/bitstream/10665/78128/3/9789 241505147_eng.pdf. Accessed October 21, 2014.

4. Adanu RM. Cervical cancer knowledge and screening in Accra, Ghana. $J$ Womens Health Gend Based Med. 2002;11(6):487-488.

5. Gaffikin L, Lauterbach M, Emerson M, Lewis R. Safety, Acceptability, and Feasibility of a Single Visit Approach to Cervical Cancer Prevention: Results from a Demonstration Project in Ghana. Baltimore, MA: JHPIEGO; 2004.

6. Duda RB, Chen GL, Hill AG, et al. Screening for cervical cancer still not included as routine health care for women. J Trop Med. 2005;1(1): $1-6$.

7. Conley M [webpage on the Internet]. New Guidelines Discourage Yearly Pap Tests; 2012 [cited March 19, 2013]. Available from: http://abcnews. go.com/blogs/health/2012/03/15/new-guidelines-discourage-yearly-paptests/. Accessed October 21, 2014.
8. Wright TC Jr, Kuhn L. Alternative approaches to cervical cancer screening for developing countries. Best Pract Res Clin Obstet Gynaecal. 2012;26(2):197-208.

9. Denny L, Kuhn L, De Souza M, Pollack AE, Dupree W, Wright TC Jr. Screen-and-treat approaches for cervical cancer prevention in lowresource settings: a randomized controlled trial. JAMA. 2005;294(17): 2173-2181

10. Global Health Group. Integrating Cervical Cancer Screening Into HIV Services in Sub-Saharan Africa: Policy brief. San Francisco, CA: Global Health Group; 2012. Available from: http://globalhealthsciences.ucsf. edu/sites/default/files/content/ghg/e2pi-integrating-cervical-cancer.pdf. Accessed October 21, 2014.

11. Abotchie PN, Shokar NK. Cervical cancer screening among college students in Ghana: knowledge and health beliefs. Int J Gynaecol Cancer. 2009;19(3):412-416.

12. Adanu RM, Seffah JD, Duda R, Darko R, Hill A, Anarfi J. Clinic visits and cervical cancer screening in Accra. Ghana Med J. 2010;44(2): 59-63.

13. Quentin W, Adu-Sarkodie Y, Terris-Prestholt F, Legood R, Opoku BK, Mayaud P. Cost of cervical cancer screening and treatment using visual inspection with acetic acid (VIA) and cryotherapy in Ghana: the importance of scale. Trop Med Int Health. 2011;16(3):379-389.

14. Ghana Districts [webpage on the Internet]. About Komenda/Edina/ Eguafo/Abirem Municipal; 2006 [cited August 15, 2013]. Available from: http://keea.ghanadistricts.gov.gh/?arrow=atd\&_=57\&sa=2764. Accessed October 21, 2014

15. Ghana Statistical Service. 2010 Population and Housing Census: Summary Report of Final Results. Accra, Ghana: Ghana Statistical Service; 2012. Available from: http://www.statsghana.gov.gh/ docfiles/2010phc/Census2010_Summary_report_of_final_results.pdf. Accessed October 21, 2014

16. Ghana Statistical Service. Ghana: 2008 Demographic and Health Survey: Key Findings. Accra, Ghana: Ghana Statistical Service; 2009. Available from: http://www.measuredhs.com/pubs/pdf/SR172/SR172. pdf. Accessed October 21, 2014.

17. NACP/GHS/MOH. 2010 HIV Sentinel Survey Report. Accra, Ghana; 2011.

18. Holmes RS, Hawes SE, Touré P, et al. HIV Infection as a risk factor for cervical cancer and cervical intraepithelial neoplasia in Senegal. Cancer Epidemiol Biomarkers Prev. 2009;18(9):2442-2446.

19. Israel GD. Determining Sample Size. Gainesville, FL: Institute of Food and Agricultural Sciences at University of Florida; 2013. Available from: http://www.edis.ifas.ufl.edu/pdffiles/PD/PD00600.pdf.

20. Burns N, Grove SK. The Practice of Nursing Research: Appraisal Synthesis and Generation of Evidence. 6th ed. Philadelphia, PA: Saunders Elsevier; 2009.

21. Mupepi SC, Sampselle CM, Johnson TR. Knowledge, attitudes, and demographic factors influencing cervical cancer screening behavior of Zimbabwean women. $J$ Womens Health (Larchmt). 2011;20(6): 943-952.

22. Robson C. Real Word Research. 3rd ed. Hoboken, NJ: John Wiley \& Sons, Inc.; 2011.

23. Central Intelligence Agency. The World Factbook. Country Statistics Ghana; 2013. Retrieved from: https://www.cia.gov/library/publications/ the-world-factbook/geos/gh.html. Accessed October 22, 2014.

24. Nwankwo KC, Aniebue UU, Aguwa EN, Anarado AN, Agunwah E. Knowledge attitude and practice of cervical cancer screening among urban and rural Nigerian women: a call for education and mass screening. Eur J Cancer Care (Engl). 2011;20(3):362-367.

25. Eze NJ, Umeora OU, Abuna JA, Egwuatu VE, Ejikeme BN. Cervical cancer awareness and cervical screening uptake at the mater Misericodiae Hospital, Afikpo, Southeast Nigeria. Ann Afr Med. 2012;11(4):238-243.

26. Balogun MR, Odukoya OO, Oyediran MA, Ujomu PI. Cervical cancer awareness and preventive practices: a challenge for female urban slum dwellers in Lagos, Nigeria. Afr J Reprod Health. 2012;16(1): $75-82$. 
27. Ndikom CM, Ofi BA. Awareness, perception and factors affecting utilization of cervical cancer screening services among women in Ibadan, Nigeria: a qualitative study. Reprod Health. 2012;9:11.

28. Getahun F, Mazengia F, Abuhay M, Birhanu Z. Comprehensive knowledge about cervical cancer is low among women in Northwest Ethiopia. BMC cancer. 2013;13:2

29. Hyacinth HI, Adekeye OA, Ibeh JN, Osoba T. Cervical cancer and pap smear awareness and utilization of pap smear test among Federal civil servants in North Central Nigeria. PLoS One. 2012;7(10):e46583.

30. Beining RM. Screening for Cervical Cancer: An Exploratory Study of Urban Women in Tamil Nadu, India [PhD thesis]. Iowa City, IA: University of Iowa; 2012.

31. Aswathy S, Quereshi MA, Kurian B, Leelamoni K. Cervical cancer screening: current knowledge and practice among women in a rural population of Kerala, India. Indian J Med Res. 2012;136(2):205-210.

32. Nadarzynski T, Waller J, Robb KA, Marlow LA. Perceived risk of cervical cancer among pre-screening age women (18-24 years): the impact of information about cervical cancer risk factors and the causal role of HPV. Sex Transm Infect. 2012;88(6):400-406.

33. Were E, Nyaberi Z, Buziba N. Perceptions of risk and barriers to cervical cancer screening at Moi Teaching and Referral Hospital (MTRH), Eldoret, Kenya. Afr Health Sci. 2011;11(1):58-64.

34. Archampong EA. Marital rape: A woman's equality issue in Ghana. Equality Effect; 2010. Available from: http://theequalityeffect.org/pdfs/ maritalrapeequalityghana.pdf. Accessed December 3, 2013.

35. Lyimo FS, Beran TN. Demographic, knowledge, attitudinal, and accessibility factors associated with uptake of cervical cancer screening among women in a rural district of Tanzania: three public policy implications. BMC Public Health. 2012;12:22.

36. Schluterman NH, Sow SO, Traore LB, et al. Differences in patterns of high-risk human papillomavirus infection between urban and rural lowresources settings: cross-sectional findings from Mali. BMC Womens Health. 2013;13:4.

37. McFadden SE, Schumann L. The role of human papillomavirus in screening for cervical cancer. J Am Acad Nurse Pract. 2001;13(3): 116-125; quiz 127-128.

38. Paolino M, Arrossi S. Women's knowledge about cervical cancer, Pap smear and human papillomavirus and its relation to screening in Argentina. Women Health. 2011;51(1):72-87.

39. Engholm G, Ferlay J, Christensen N, et al. NORDCAN - a Nordic tool for cancer information, planning, quality control and research. Acta Oncol. 2010;49(5):725-736.
40. Jemal A, Center MM, DeSantis C, Ward EM. Global patterns of cancer incidence and mortality rates and trends. Cancer Epidemiol Biomarkers Prev. 2010;19(8):1893-1907.

41. Ezem BU. Awareness and uptake of cervical cancer screening in Owerri, South-Eastern Nigeria. Ann Afr Med. 2007;6(3):94-98.

42. Chirenje ZM, Rusakaniko S, Kirumbi L, et al. Situation analysis for cervical cancer diagnosis and treatment in east, central and southern African countries. Bull World Health Organ. 2001;79(2):127-132.

43. Obi SN, Ozumba BC, Nwokocha AR, Waboso PA. Participation in highly subsidized cervical cancer screening by women in Enugu, South-east Nigeria. J Obstet Gynaecol. 2007;27(3):305-307.

44. Kwok C, White K, Roydhouse JK. Chinese-Australian women's knowledge, facilitators and barriers related to cervical cancer screening: a qualitative study. J Immigr Minor Health. 2011;13(6):1076-1083.

45. Kivistik A, Lang K, Baili P, Anttila A, Veerus P. Women's knowledge about cervical cancer risk factors, screening, and reasons for nonparticipation in cervical cancer screening programme in Estonia. BMC Womens Health. 2011;11:43.

46. Donnelly TT, Al Khater AH, Al-Bader SB, et al. Beliefs and attitudes about breast cancer and screening practices among Arab women living in Qatar: a cross-sectional study. BMC Womens Health. 2013;13:49.

47. Obeidat BR, Amarin ZO, Alzagnal L. Awareness, practice and attitude to cervical Papanicolaou smear among female health care workers in Jordan. Eur J Cancer Care (Engl). 2012;21(3):372-376.

48. Williams MS, Amoateng P. Knowledge and beliefs about cervical cancer screening among men in Kumasi, Ghana. Ghana Med J. 2012;46(3): $147-151$.

49. Waller J, Bartoszek M, Marlow L, Wardle J. Barriers to cervical cancer screening attendance in England: a population-based survey. J Med Screen. 2009;16(4):199-204.

50. Ackerson K, Gretebeck K. Factors influencing cancer screening practices of underserved women. JAm Acad Nurse Pract. 2007;19(11): 591-601.

51. Mutyaba T, Mmiro FA, Weiderpass E. Knowledge, attitudes and practices on cervical cancer screening among the medical workers of Mulago Hospital, Uganda. BMC Med Educ. 2006;6:13.

52. Sudenga SL, Rositch AF, Otieno WA, Smith JS. Knowledge, attitudes, practices, and perceived risk of cervical cancer among Kenyan women: brief report. Int J Gynecol Cancer. 2013;23(5):895-899.
International Journal of Women's Health

\section{Publish your work in this journal}

The International Journal of Women's Health is an international, peerreviewed open-access journal publishing original research, reports, editorials, reviews and commentaries on all aspects of women's healthcare including gynecology, obstetrics, and breast cancer. The manuscript management system is completely online and includes

\section{Dovepress}

a very quick and fair peer-review system, which is all easy to use. Visit http://www.dovepress.com/testimonials.php to read real quotes from published authors. 